\title{
Perbandingan Metode Pengajaran Review Video dengan tanpa Review Video terhadap Keberhasilan dan Lama Intubasi pada Mahasiswa Program Studi Pendidikan Dokter
}

\author{
Ferawati, ${ }^{1}$ Dedi Fitri Yadi, ${ }^{2}$ Erwin Pradian ${ }^{2}$ \\ ${ }^{1}$ Rumah Sakit Umum Pusat Fatmawati Jakarta Selatan, \\ ${ }^{2}$ Departemen Anestesiologi dan Terapi Intensif \\ Fakultas Kedokteran Universitas Padjadjaran/RSUP Dr. Hasan Sadikin Bandung
}

\begin{abstract}
Abstrak
Metode pengajaran yang inovatif dan efektif dalam pengajaran intubasi endotrakeal dibutuhkan untuk untuk menghasilkan mahasiswa kedokteran yang memiliki keterampilan memadai. Metode pengajaran review video yang melibatkan dual coding theory menggunakan kombinasi antara gambar dan suara akan mengaktifkan saluran kognitif verbal dan nonverbal sehingga dapat membantu memahami informasi dengan lebih baik. Penelitian ini bertujuan mengetahui perbandingan keberhasilan dan lama intubasi endotrakeal pada manekin menggunakan metode pengajaran review video dengan tanpa review video yang dilakukan oleh mahasiswa Program Studi Pendidikan Dokter (PSPD). Penelitian menggunakan metode randomized crossover study, dilakukan di RSUP Dr. Hasan Sadikin (RSHS) Bandung pada bulan Juli-September 2019 dan melibatkan 60 mahasiswa PSPD. Data kategorik dianalisis menggunakan Uji Eksak Fisher dan data numerik menggunakan Uji Mann Whitney. Penelitian ini memberikan hasil keberhasilan intubasi kelompok metode pengajaran review video $96,7 \%$ dan metode pengajaran tanpa review video $73,3 \%(p<0,05)$, lama intubasi rerata kelompok metode pengajaran review video 101,1 detik dan metode pengajaran tanpa review video 126,8 detik $(\mathrm{p}<0,05)$. Simpulan penelitian adalah penggunaan metode pengajaran review video meningkatkan keberhasilan intubasi dan mempersingkat lama intubasi oleh mahasiswa kedokteran.
\end{abstract}

Kata kunci: Intubasi endotrakeal, keberhasilan intubasi, lama waktu intubasi, metode pengajaran review video

\section{Comparison of Teaching Method with and without Video Review on Intubation Success Rate and Time Performed by Medical Students}

\begin{abstract}
Innovative and effective teaching methods in teaching endotracheal intubation are needed to produce sufficient skills among medical students. Video review teaching methods that involve a dual coding theory using a combination of images and sound activate verbal and nonverbal cognitive channels, leading to better understanding of the information conveyed. This study aimed to compare the success and duration of endotracheal intubation in mannequins using the video review teaching method compared to teaching without video review to students of the Medical Education Study Program (Program Studi Pendidikan Kedokteran, PSPD). This was a randomized crossover study conducted in Dr. Hasan Sadikin General Hospital Bandung in July-September 2019 on 60 PSPD students. Categorical data collected were analyzed using the Fisher's Exact Test while Mann Whitney test was used for numerical data. It was identified that the success rate of intubation performed by the group receiving video review was $96.7 \%$ while the non-video review group achieved a success rate of $73.3 \%(\mathrm{p}<0.05)$. The average length of intubation in the video review group was 101.1 seconds while the non-video review group performed intubation in 126.8 seconds $(\mathrm{p}<0.05)$. Therefore, the use of video review teaching method increases the success of intubation and shorten the length of time intubation by medical students.
\end{abstract}

Key words: Endotracheal intubation, intubation time, successful intubation, video review method

Korespondensi: Ferawati, dr, SpAn, Rumah Sakit Umum Pusat Fatmawati Jakarta Selatan, Jl. TB. Simatupang C No. 18 Cilandak Barat, Kec. Cilandak, Kota Jakarta Selatan, Daerah Khusus Ibukota Jakarta 12430, Tlpn (021) 7501524, Email: ferawatiardian@gmail.com 


\section{Pendahuluan}

Penanganan jalan napas adalah komponen resusitasi yang penting terutama pada pasien kritis. ${ }^{1}$ Intubasi endotrakeal merupakan baku emas dalam penanganan jalan napas untuk memberikan ventilasi dan oksigenasi. Intubasi diindikasikan untuk proteksi jalan napas dan kontrol jalan napas pada pasien dengan risiko aspirasi, penyakit saluran napas atas, ventilasi mekanik, resusitasi, dan berbagai bentuk distres napas akut. Walaupun rutin dilakukan di bidang anestesi dan memiliki tingkat keberhasilan yang tinggi, intubasi bukanlah prosedur tanpa risiko. Intubasi merupakan salah satu penyebab utama terjadinya cedera iatrogenik. . $^{1-4}$

Intubasi merupakan keahlian penting yang harus dimiliki oleh tenaga medis. Oleh karena itu, diperlukan pengajaran intubasi dengan metode dan durasi yang efektif kepada mahasiswa kedokteran agar memiliki keahlian intubasi yang memadai. Selama masa pendidikan, mahasiswa harus mampu melakukan intubasi endotrakeal, suatu prosedur yang menantang. ${ }^{5}$

Pengajaran intubasi endotrakeal paling baik dengan metode simulasi pada pasien menggunakan laringoskopi direk. Namun, simulasi langsung pada pasien saat ini terkendala karena waktu dan kesempatan yang terbatas dan prinsip bioetika. Oleh karena itu, fokus dunia pendidikan saat ini telah bergeser ke arah mempersiapkan tenaga medis yang kompeten dengan metode pembelajaran simulasi menggunakan manekin. Beberapa alat bantu dan metode pengajaran dapat digunakan untuk meningkatkan pengetahuan dan kemampuan tersebut, salah satunya menggunakan alat multimedia. ${ }^{6}$

Salahsatuaspekpentingmetodepengajaran adalah supervisi dan umpan balik terstruktur. Metode pengajaran simulasi dengan proses perekaman simulasi yang dilanjutkan dengan umpan balik dari supervisor dan review video perekaman atas kinerja sendiri secara intuitif diketahui bermanfaat bagi pengembangan kognitif maupun teknis. Berbagai profesi telah melakukan review video. Review secara kritis rekaman video penampilan merupakan bagian dari upaya perbaikan di masa depan. Hal ini dapat diterapkan juga dalam pendidikan kedokteran. Metode pengajaran review video yang melibatkan dual coding theory menggunakan kombinasi antara gambar dan suara akan mengaktifkan saluran kognitif verbal dan nonverbal sehingga dapat membantu memahami informasi dengan lebih baik. Dua saluran kognitif ini membuat proses pembelajaran mengenai sesuatu akan lebih mudah karena mengurangi beban kerja memori pada tiap-tiap saluran kognitif. ${ }^{6,7}$

Pada penelitian ini dilakukan perbandingan antara metode pengajaran intubasi endotrakeal dengan review video dan tanpa review video terhadap keberhasilan dan lama intubasi pada mahasiswa PSPD. Penelitian ini merupakan modifikasi penelitian sebelumnya yang dilakukan di Amerika pada tahun 2009 dan Kanada pada tahun 2016. ${ }^{7,8}$

Tujuan penelitian ini adalah mengetahui perbandingan keberhasilan intubasi endotrakeal dan lama intubasi endotrakeal menggunakan metode pengajaran review video dengan tanpa review video pada intubasi yang dilakukan oleh mahasiswa PSPD.

\section{Subjek dan Metode}

Penelitian ini menggunakan metode analitik eksperimental prospektif randomized crossover study. Pengambilan sampel dilakukan secara consecutive sampling dan dilakukan randomisasi subjek ke dalam salah satu kelompok. Penelitian dilakukan di Departemen Anestesiologi dan Terapi Intensif RSUP Dr. Hasan Sadikin pada bulan Juli-September 2019 setelah mendapatkan persetujuan dari Komisi Etik Penelitian Kesehatan dan disetujui oleh Rumah sakit. Penelitian ini melibatkan mahasiswa PSPD dan menggunakan manekin.

Subjek penelitian adalah mahasiswa PSPD yang menjalani rotasi di Bagian Anestesiologi dan Terapi Intensif FK Universitas Padjadjaran, RSUP Dr. Hasan Sadikin Bandung. Pemilihan subjek berdasar kriteria inklusi mahasiswa program studi pendidikan dokter yang sedang menjalani rotasi di Bagian Anestesiologi dan 
Terapi Intensif FK Universitas Padjadjaran dan kriteria eksklusi adalah mahasiswa program studi pendidikan dokter yang pernah melakukan intubasi pada manusia atau manekin sebelumnya. Responden yang ikut serta adalah responden yang memenuhi kriteria inklusi dan bersedia mengikuti penelitian setelah diberikan penjelasan dan menandatangani formulir persetujuan (informed consent).

Subjek penelitian terdiri atas 60 orang yang terbagi menjadi dua kelompok. Kelompok A terdiri atas 30 mahasiswa PSPD yang menjalani pengajaran intubasi melalui umpan balik langsung dari instruktir tanpa review video dan kelompok B terdiri atas 30 mahasiswa PSPD yang menjalani pengajaran intubasi dengan review video bersama instrukstur setelah sesi simulasi selesai. Kemudian dilakukan penilaian keberhasilan dan lama intubasi pada kedua kelompok.

Peralatan yang digunakan dalam penelitian ini meliputi manekin dewasa merek Laerdal Airway Management Trainer, videolaringoskopi C-MAC, blade nomor 3, bag valve mask merek Laerdal, pipa endotrakeal ukuran no. 7.0 merek Aximed, stilet intubasi, spuit $10 \mathrm{cc}$, stopwatch, buku pencatat, dan video kamera smartphone merek Xiaomi Redmi 5.

Prosedur penelitian adalah subjek mendapatkan materi mengenai intubasi endotrakeal dengan sistem lecture. Setelahnya, subjek melihat demonstrasi intubasi endotrakeal oleh instruktur dan diberikan kesempatan untuk bertanya. Kemudian, subjek dibagi menjadi dua kelompok, yaitu kelompok metode pengajaran review video dan tanpa review video serta dilakukan pembimbingan oleh instruktur. Pada siang hari setelah pembimbingan, dilakukan penilaian keberhasilan dan lama intubasi. Seluruh subjek melakukan intubasi ke manekin terstandar. Keberhasilan dan lama intubasi endotrakeal dinilai dan dicatat. Keberhasilan intubasi tercapai jika subjek berhasil memasukkan pipa endotrakeal ke dalam rongga trakea ditandai dengan pipa endotrakeal melewati pita suara. Lama intubasi adalah lama waktu yang dibutuhkan mulai dari ujung bilah laringoskop melewati bibir sampai pipa endotrakeal berada di trakea.

Uji statistik penelitian ini menggunakan Uji Eksak Fisher dan Mann Whitney. Data hasil penelitian dicatat dan diolah menggunakan program statistical product and service solution (SPSS) versi 24.0 for windows.

\section{Hasil}

Gambaran karakeristik subjek penelitian berdasar usia dan jenis kelamin (Tabel 1).

Keberhasilan intubasi pada kelompok metode pengajaran review video lebih tinggi dibanding dengan kelompok tanpa review video $(\mathrm{p}<0,05$; Tabel 2$)$.

Tabel 1 Karakteristik Subjek Penelitian

\begin{tabular}{lccc}
\hline & \multicolumn{2}{c}{ Metode Pengajaran } & \\
\cline { 2 - 3 } Usia dan Jenis Kelamin & $\begin{array}{c}\text { Review } \text { Video } \\
\mathbf{n = 3 0}\end{array}$ & $\begin{array}{c}\text { Tanpa Review } \text { Video } \\
\mathbf{n = 3 0}\end{array}$ & Nilai p \\
\hline Usia (tahun) & & & 0,47 \\
Median & 21,00 & 21,00 & 0,59 \\
Range (min.-maks.) & $20,00-22,00$ & $20,00-23,00$ & \\
Jenis kelamin & 10 & 12 & 18 \\
Laki-laki & 20 & & \\
Perempuan & & & \\
\hline
\end{tabular}

Keterangan: data numerik nilai p diuji dengan Uji Mann Whitney. Data kategorik nilai p dihitung berdasar uji chisquare 
Tabel 2 Perbandingan Angka Keberhasilan Intubasi

\begin{tabular}{|c|c|c|c|}
\hline \multirow[b]{2}{*}{$\begin{array}{l}\text { Keberhasilan } \\
\text { Intubasi }\end{array}$} & \multicolumn{2}{|c|}{ Metode Pengajaran } & \multirow[b]{2}{*}{ Nilai p } \\
\hline & $\begin{array}{c}\text { Review Video } \\
\mathrm{n}=\mathbf{3 0}\end{array}$ & $\begin{array}{c}\text { Tanpa Review Video } \\
\qquad \mathbf{n}=30\end{array}$ & \\
\hline Berhasil & 29 & 22 & \multirow{2}{*}{$0,026^{* *}$} \\
\hline Tidak berhasil & 1 & 8 & \\
\hline
\end{tabular}

Lama intubasi yang dibutuhkan dengan metode pengajaran review video lebih pendek secara signifikan dibanding dengan metode pengajaran tanpa review video $(\mathrm{p}<0,001$; Tabel 3).

\section{Pembahasan}

Institusi pendidikan dituntut untuk menciptakan metode pengajaran alternatif yang dapat meningkatkan keterampilan klinis secara optimal tanpa harus melibatkan pasien secara langsung. Salah satu metode pengajaran yang unggul adalah dengan simulasi terhadap manekin disertai diskusi yang melibatkan audio atau verbal. Walaupun demikian, setelah menyelesaikan pendidikan, tenagatenaga medis pemula masih mengalami stres dalam praktik klinis karena takut membuat kesalahan di depan pasien sehingga diperlukan metode pengajaran yang inovatif dan terus berkembang. ${ }^{9}$

Metode pengajaran alternatif yang dapat digunakan, yaitu metode pengajaran review video yang terus berkembang bersamaan dengan penggunaan teknologi yang semakin maju. Pembelajaran dengan review video mengimplementasikan teori dual coding yang menjelaskan bahwa dua saluran kognitif, yaitu fungsi proses objek visual atau nonverbal dan auditorial atau verbal yang terintegrasi akan mengurangi beban kerja memori. Metode review video juga meningkatkan motivasi belajar karena mahasiswa dapat menilai diri sendiri dan mengevaluasi kemampuan secara mandiri. ${ }^{6}$

Menurut teori proses kerja kognitif oleh Sweller terdapat tiga beban kognitif, yaitu extraneous, intrinsic, dan germane. Beban intrinsic mengacu pada tingkat kesulitan materi dan interaktivitas antara elemen materi. Semakin rumit materi yang dipelajari maka beban intrinsic semakin tinggi. Beban extraneous mengacu pada elemen-elemen tidak penting di luar materi dan desain pelajaran yang tidak efisien. Beban germane adalah beban kognitif yang muncul ketika kita memroses informasi dan membentuk memori dari materi yang dipelajari. Kapasitas memori yang tersisa dari beban extraneous dan instrinsic digunakan untuk proses germane dalam merealisikan pelajaran menjadi memori. Dalam pengajaran dengan multimedia, termasuk review video, beban

\section{Tabel 3 Perbandingan Lama Intubasi}

\begin{tabular}{lccc}
\hline \multirow{2}{*}{$\begin{array}{c}\text { Lama Intubasi } \\
\text { (Detik) }\end{array}$} & \multicolumn{2}{c}{ Metode Pengajaran } & \\
\cline { 2 - 3 } & Review Video & Tanpa Review Video & Nilai p \\
\hline Mean \pm Std & $101,10 \pm 18,12$ & $\mathbf{n = 3 0}$ & $0,0001^{* *}$ \\
Median & 97,50 & $126,83 \pm 29,34$ & 119,00 \\
\hline
\end{tabular}

Keterangan: data numerik nilai $\mathrm{p}$ diuji dengan Uji Mann Whitney. Nilai kemaknaan berdasar nilai $\mathrm{p}<0,05$. Tanda* menunjukkan nilai $\mathrm{p}<0,05$ artinya signifkan atau bermakna secara statistik 
kerja extraneous harus diminimalisasi dengan menyediakan sarana belajar yang terfokus sehingga kapasitas memori yang tersisa untuk germane semakin banyak. Penelitian ini telah disusun sehingga faktor-faktor yang dapat membebani proses kerja kognitif subjek penelitian dapat diminimalisasi. ${ }^{6,10}$

Penelitian ini menunjukkan bahwa penggunaan metode pengajaran review video dapat meningkatkan keberhasilan mahasiswa kedokteran dalam melakukan tindakan intubasi dan dapat mengurangi lama intubasi endotrakeal dibanding dengan metode pengajaran tanpa review video. Hasil penelitian ini sesuai dengan penelitian lain pada residen bedah di Amerika mengenai pengajaran tindakan penjahitan pada laparoskopi. Penelitian tersebut membandingkan antara dua kelompok, yaitu kelompok yang mendapat rekaman pengerjaannya sendiri untuk direview di rumah dan kelompok yang tidak. Pada penelitian tersebut, waktu pengerjaan pada kelompok yang memperoleh review video berkurang hingga 30,3\% dibanding dengan kelompok tanpa review video yang memperoleh pengurangan waktu pengerjaan hanya $3,1 \%$. Hasil penelitian tersebut sesuai dengan penelitian ini bahwa lama pengerjaan intubasi pada kelompok review video lebih singkat dibanding dengan kelompok tanpa review video. ${ }^{7}$

Hasil penelitian ini berbeda dengan penelitian sebelumnya di Rumah Sakit Hasan Sadikin Bandung mengenai perbandingan informasi verbal dengan presentasi video terhadap pengetahuan prosedur anestesi umum pada pasien. Pada penelitian tersebut, tidak didapatkan perbedaan yang bermakna antara informasi yang disampaikan secara verbal dan video. Hal ini berbeda dengan penelitian ini yang menunjukkan bahwa review video memberikan luaran yang lebih baik. Perbedaan ini dapat terjadi karena pada penelitian tersebut, subjek penelitian adalah pasien-pasien yang mungkin memeroleh informasi medis yang berbeda-beda di luar penelitian, tingkat kepuasan pasien terhadap pemberian informasi yang beragam, dan perbedaan tingkat kecemasan pasien yang dapat memengaruhi penyampaian informasi sehingga menjadi bias pada penelitian tersebut. Hal ini tidak diperoleh pada penelitian ini karena subjek penelitian yang lebih homogen, yaitu mahasiswa PSPD dengan latar belakang medis yang hampir setara. ${ }^{10}$

Hasil penelitian ini juga tidak sesuai dengan penelitian terdahulu yang dilakukan pada mahasiswa kedokteran yang sedang menjalani rotasi anestesi di Kanada. Penelitian tersebut membandingkan pembelajaran intubasi endotrakeal dengan laringoskopi direk, laringoskopi visual dengan umpan balik langsung, dan laringoskopi video dengan umpan balik langsung disertai perekaman video. Pada penelitian tersebut, tidak didapatkan keunggulan dari kelompok laringoskopi video yang disertai review video dibanding dengan yang tidak. Hal ini berbeda dengan penelitian ini yang menyatakan bahwa laringoskopi video disertai review video lebih unggul dalam rerata lama intubasi dibanding dengan kelompok tanpa review video. Perbedaan hasil ini mungkin disebabkan oleh tingkat perekaman tindakan laringoskopi dan angka review video yang rendah hanya $71 \%$ dari kelompok review video yang direkam pada penelitian Sainsbury sehingga data yang diperoleh tidak valid. Pada penelitian ini $100 \%$ subjek pada kelompok review video dilakukan perekaman. Selain itu, pada penelitian tersebut hasil perekaman di-review secara mandiri oleh subjek tanpa didampingi oleh instruktur. ${ }^{8}$

Keterbatasan pada penelitian ini adalah setelah dilakukan pembimbingan oleh instruktur tidak ada data dasar mengenai pengetahuan dan kemampuan subjek penelitian tentang intubasi. Setelah kedua kelompok melakukan pelatihan intubasi, pada kelompok B selanjutnya melakukan review video dan kemudian semua subjek langsung dinilai. Oleh karena itu, progresivitas keberhasilan intubasi endotrakeal memakai metode pengajaran ini tidak dapat dinilai.

\section{Simpulan}

Penggunaan metode pengajaran review video meningkatkan keberhasilan mahasiswa 
kedokteran dalam melakukan tindakan intubasi dan menghasilkan lama intubasi endotrakeal yang lebih singkat dibanding dengan metode pengajaran tanpa review video.

\section{Daftar Pustaka}

1. Warner KJ, Carlbom D, Cooke CR, Bulger EM, Copass MK, Sharar SR. Paramedic training for proficient prehospital endotracheal intubation. Prehosp Emerg Care. 2010;14:103-8.

2. Kavitha J, Tripathy DK, Mishra SK, Mishra G, Chandrasekhar LJ, Ezhilarasu P. Intubating condition, hemodynamic parameters and upper airway morbidity: a comparison of intubating laryngeal mask airway with standard direct laryngoscopy. Anesth Essays Res. 2011;5(1):48-56.

3. Morgan G, Mikhail M. Airway management. Edisi ke-6. Butterworth J, Mackey D, Wasnick J, penyunting. New York: McGrawHill; 2018. hlm. 320-8.

4. Ceylan C, Kaya S, Sumancilar O, Usluer O, Gursoy S, Uevet A. Intraoperative management of tracheobronchial rupture after double-lumen tube intubation. Surg Today. 2013;43:757-62.

5. Johnston BD, Seitz SR, Wang HE. Limited opportunities for paramedic student endotracheal intubation training in the operating room. Acad Emerg Med. 2006;13(10):1051-5.

6. Suryo Ananto Y, Sitanggang RH, Kestriani ND. Perbandingan pemberian informasi verbal dengan presentasi video terhadap pengetahuan prosedur anestesi umum pada pasien yang akan menjalani operasi di RSUP Dr. Hasan Sadikin Bandung. JAP. 2018;6(3):183-92.

7. Jamshidi R, LaMaster T, Eisenberg. Video self-assesment augments development of videoscopic suturing skill. J Am Coll Surg. 2009;209:622-5.

8. Sainsbury JE, Telgarsky B, Parotto $M$, Niazi A, Wong DT, Cooper RM. The effect of verbal and video feedback on learning direct laryngoscopy among novice laryngoscopists: a randomized pilot study. Can J Anaesth. 2016;64:252-9.

9. Parish, SJ, Weber CM, Steiner-Grossman P, Milan FB, Burton WB, Marantz PR. Applied research: teaching clinical skills through videotape review: a randomized trial of group versus individual reviews. Teach Learn Med. 2006;18(2):92-8

10. Mutlu-Bayraktar D, Cosgun V, Altan T. Cognitive load in multimedia learning environments: a systematic review. Computers Educat. 2019;141:103618. 